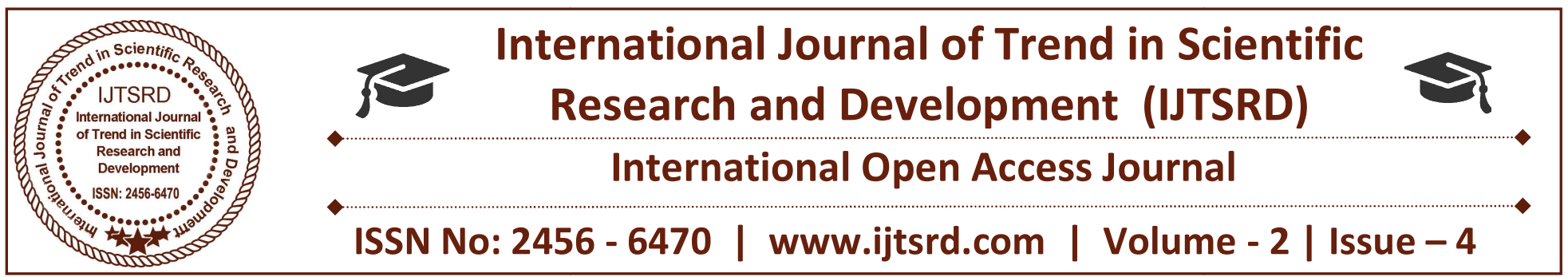

\title{
Experimental study on flexible concrete by using polyurethane fiber
}

\author{
Dinesh W. Gawatre', Ajay G. Gaund², Dipali S. Dhondge², Amol U. Gandhale², Shubham Fartade ${ }^{2}$ \\ ${ }^{1}$ Assistant Professor, Department of Civil Engineering, SAOE, Kondhwa (bk), Pune, Maharashtra, India \\ ${ }^{2}$ Student, Department of Civil Engineering, SAOE, Kondhwa (bk), Pune, Maharashtra, India
}

\section{ABSTRACT}

In this paper the properties of conventional concrete have been developed. Conventional concrete has the property of high brittleness and less flexural strength. This is a undesirable characteristics is mother of development of Flexible concrete to improve this deficiency. The Polyurethane fiber has the ability to impart considerably flexibility in concrete. For this purpose concrete cube, cylinders and beams experimentally tested. By the mixture of traditional concrete ingredients and special polyurethane fibers addition with water super plasticizers for good workability purpose. The test results have proved to be increased flexibility of the concrete.

Keywords: Flexural strength, split tensile strength, compressive strength, Polyurethane fiber

\section{INTRODUCTION}

Concrete is a mixture of cement, coarse aggregates and that sets after mixing with water in proportion at certain chemical reaction. In old days concretes were lime-based concretes in which binding material was lime. After some development Portland cement concrete, hydraulic cements, were used. Before cement concrete road, asphalt concrete is used for pavement surfaces, where bitumen is used as cementitious material. Concrete is much strong in compressive strength, but much lower in tensile strength. To improve tensile strength it is reinforced with steel that are strong in tension. The elasticity of conventional concrete is generally constant at low stress levels but as the stress level increases it starts decreasing as micro cracking develop. It is much weak in coefficient of thermal expansion and as the stress increases it shrinks. The structures made from conventional concrete develops crack at, due to shrinkage, tensile stress and creep.CC is very rigid and has much lower in strain of about $0.1 \%$. that makes CC highly brittle and hard. It structure causes failure under strain due to deficiency in flexibility. To overcome this deficiency Flexible Concrete is developed. Which is prepared by mixing polyurethane fiber in $\mathrm{CC}$ with proper mix design. This Polyurethane is able to develops required flexibility. Flexible concrete is mixture of the same materials we used for CC, Additionally with Polyurethane fiber and super plasticizer for Water Reducing and to improve workability. Flexible concrete uses less amounts of fiber generally up to $2 \%$ by volume of aggregates. At flexural stress the beam can deflect well without direct failure. The various ingredients of Flexible Concrete work together to share the applied load. Flexible concrete has proved to be more in flexural strength than Conventional concrete. It has good energy absorbing property which makes FC suitable for seismic prone area Conventional concrete suffers direct failure. When stressed or strained in an heavy load, creep load or an earthquake and that of Flexible concrete remain safe to use at tensile strain up to $150 \%$ of conventional concretes. While selecting polyurethane fiber for flexible concrete. It was found that PU fiber was of low cost and high performance. This fiber has high bonding property with cementitious material. It has high abrasive nature, zero water absorption, highly elastic property. This fiber is widely used in civil engineering constructions such as pavements, building members in seismic prone area. 
International Journal of Trend in Scientific Research and Development (IJTSRD) ISSN: 2456-6470

\section{OBJECTIVES:}

* The main purpose is to increase the flexural strength of the concrete.

To make concrete flexible and self-healing.

To improve tensile behavior of concrete

To increase strain capacity and increase elasticity.

To improve the quality of the rigid pavement.

To improve split tensile strength.

\section{APPLICABILITY OF THE F.C.:}

* In seismic resisting structure, high ductility in the flexible concrete can make a noticeable difference in a seismic structure.

* In the road construction work it is applicable as pavement having crack resisting property having high flexural strength for long durability.

For good aesthetic architectural design. result in polycarboxylates based super plasticizer mix than sulphonated melamine formaldehyde based super plasticizer .

S.Uttamraj, K.Ashwanath, Dr.Md.Rafeeq has examined that Results between comparison of conventional concrete with fly ash of $30 \%$ and ECC made with PVA fiber with $30 \%$ of fly ash. Due to fly ash The conventional concrete shows reduce workability. But it is improved by adding super plasticizer. This paper showed that there was significant increase in flexural strength with increase in fiber content. The compressive strength is more in less percent of fiber used. But split tensile strength and flexural strength was $49 \%$ increased and was $48 \%$ increased as compared to conventional concrete.

U. L. Deshpande1, Pranesh B Murnal2According to test results, the member is withstanding with heavy load and a large deformation without failure to the brittle fracture, even steel reinforcement were not used. Conventional concrete has brittle behavior where ECC has ductile nature. Flexural strength of $\mathrm{ECC}$ is $60 \%$ more than conventional concrete, with nearly same compressive strength of ECC and conventional concrete. Split tensile strength of ECC is $32 \%$ more than CC. The cost of ECC is about two to three times that of CC. The advantages of ECC is more compared with conventional concrete. As the use of fly ash gives less environmental impact because disposal of fly ash is serious issue, hence Eco Friendly.

\section{METHODOLOGY:}

1. The materials essential for the project work are to be procured of predetermined grade and quality. This research is having requirement of materials. Cement, Sand Aggregate, Polyurethane

\section{LITERATURE REVIEW:}

2. Basic property tests on cement ( Standard consistency test, Setting time test, Fineness test, Compressive test ), sand (specific gravity test, Fineness test) and coarse aggregate (specific gravity test, flakiness and Elongation test, Fineness test ) are conducted properly.

3. Prepared Mix design for M30 grade concrete.

ultimate tensile strength of ECC. As the fiber size is increased the compressive strength and stiffness decreases. If the fibers are kept perpendicular to the shear plane Then ductility in direct shear significantly improved when the fibers are perpendicular to the shear plane. The workability of concrete gives higher
4. Take PU fiber of required size and shape in various percentage $(0.1 \%, 0.2 \%, 0.3 \%, 0.4 \%)$ of coarse aggregate. 
5. Preparation of standard cube $(150 \mathrm{~mm} \times 150 \mathrm{~mm} \times$ $150 \mathrm{~mm})$, cylinders $(\mathrm{d}=300 \mathrm{~mm}$, dia. $=150 \mathrm{~mm})$, beam $(150 \mathrm{~mm} \times 700 \mathrm{~mm} \times 150 \mathrm{~mm})$ of varying percentage of fiber. 3 items of each, including conventional concrete.

6. Test these specimens on the CTM, UTM and take the mean of 3 results of same kind for accuracy.

7. These results of Flexible Concrete compare e with Conventional Concrete and represented in graphically manner.

\section{TESTING AND RESULTS:-}

\section{COMPRESSIVE TEST:}

The compressive strength test is carried out in order to prove that the compressive strength of bendable is not significantly more the FRC but the compressive strain in bendable concrete is about $50-70 \%$ more than that of normal \& FRCs. Defined as compressive strength of concrete specimen after 7 days, 14 days and 28 days of curing. Compressive strength $=$ force $/$ area .

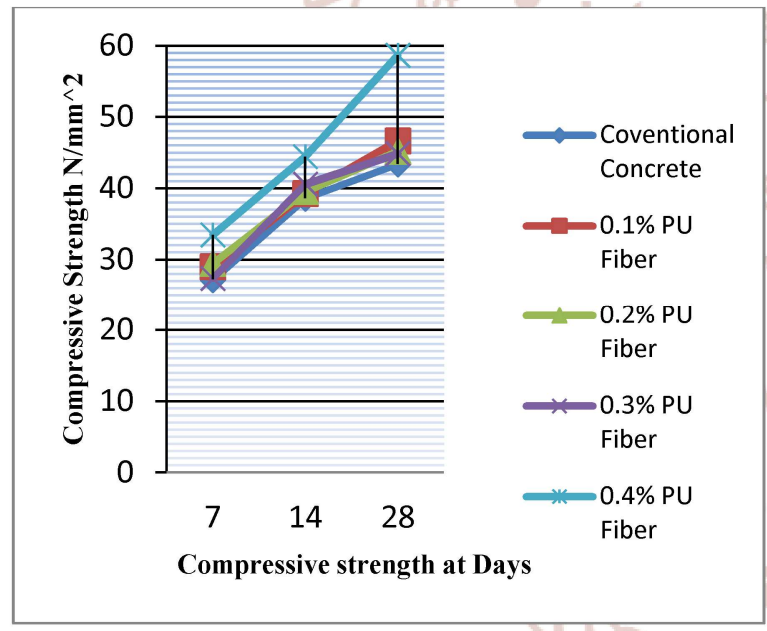

Graph 1: Comparison of Compressive strength in between $\mathrm{CC}$ and F.C.

\section{SPLIT TENSILE STRENGTH:}

The tensile strength of concrete is measured in three ways: direct tension, splitting tension, and flexural. It is difficult to test concrete in direct (uniaxial) tension because of the problem of gripping the specimen satisfactorily and because there must be no eccentricity of the applied load. Therefore, direct tensile test is not standardized and rarely used. Modulus of rupture test and splitting test are commonly used to determine the tensile strength of concrete. $\mathrm{Fct}=2 \mathrm{P} /$ pi.1.d
Graphical representation of test results:

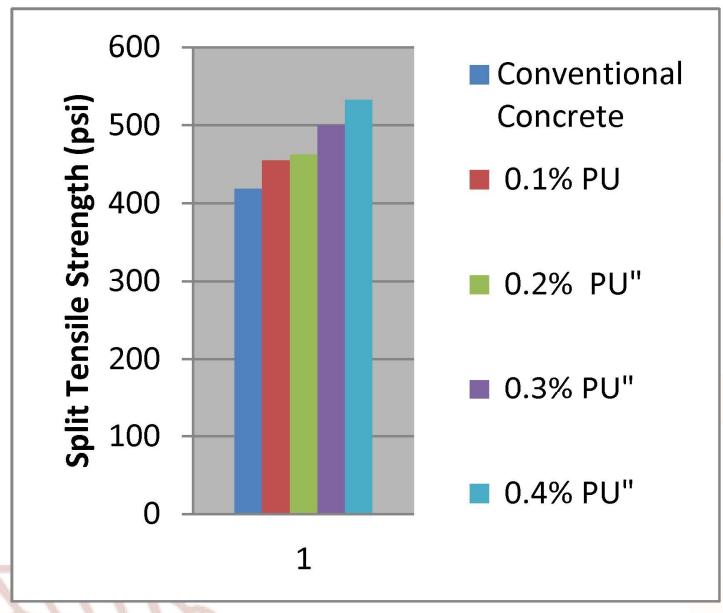

Graph 2: comparison between split tensile strength of C.C.\&F.C.

\section{FLEXURAL STRENGTH TEST:-}

This test is carried to check the deflection \& selfhealing property of the flexible concrete. And to determine nature of flexible concrete under the flexural stresses. that is the strength of a member to resist failure in bending. this test is carried out by measuring loading on unreinforced 150x150x700 mm concrete beams. The flexural strength is in general called as "Modulus of Rupture" (MR) in MPa. The relation between material and its $M R$.

Modulus of Rupture $=3 \mathrm{PL} / 2 \mathrm{bd}^{\wedge} 2$

Graphical representation of test results:

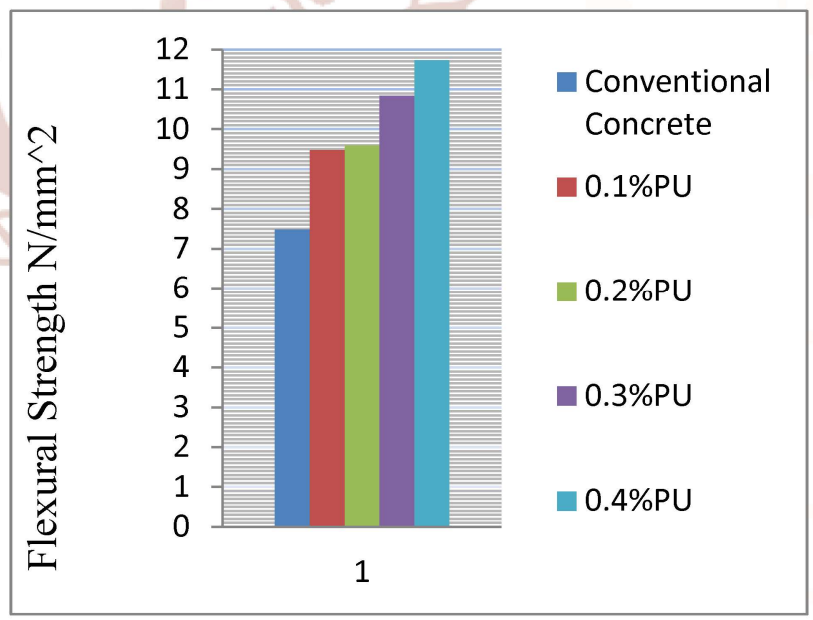

Graph3: comparison of flexural strength in between C.C. and F.C.

\section{CONCLUSION:}

1. From the analyzed data and the results it proves that the strength of Flexible Concrete is increasing 
as the percentage of PU fiber accordingly increased. As the mix design, environmental condition, temperature and all other parameters were kept same as that of conventional concrete. There is just a variation of percentage of PU fiber used in concrete. The Flexible Concrete gives more Compressive strength, Flexural strength and Split Tensile strength as per Graph no:1, Graph no:2, Graph no:3.

2. In this project the compression and flexural strength of concrete are compared with conventional concrete are increased. Therefore it is proved that the bendable concrete is more strength than the conventional concrete and it is more flexible so that it resists cracks and acts as self healing and gives more efficiency in seismic regions.

3. It is much tougher and has good compressive strength for 7 days, 14 days and 28 days and The split tensile strength of the FC concrete is much better when compared to the conventional concrete.

4. It was observed that by physical appearance on PU-FC specimen has greater crack control as can be seen on surface reduction of crack widths and crack spacing. For conventional concrete it was observed that micro cracks and surface crack were more when compared to FC.

5. The study of this paper shows that as the fiber content is increases in the members the flexural strength increases.

\section{REFERENCE:}

1. S.Uttamraj1, K. Ashwanth2, Dr. Md.Rafeeq3 1(Research scholar, JNTUH/, INDIA) 2(civil dept, AURORA, Bandlaguda, INDIA) 3(Research Officer TSERL Himayat Sagar INDIA) An comparative study on Conventional concrete and Engineered Cementitious Composites(ECCPVA)- REVIEW

2. U.L. Deshpande1, Pranesh B Murnal2. Government College of Engineering, Karad415124, India. Government College of Engineering, Aurangabad, India Ductile Concrete Using Engineered Cementitious Composites.
3. Sagar Gadhiya1 Prof. T. N. Patel2 Dr. Dinesh Shah3. 1PG Student 2,3Assistnat Professor1,2Department of Civil Engineering Department of Architecture Engineering 1,2,3Sardar Vallabhbhai Institute of Technology (Vasad),Gujarat Technological University. Parametric Study on Flexural Strength of ECC.

4. Satheesh v s1, Yuvaraja n2, Vinoth v2, Balaji p2, Abhinav Gurung2. 1.Adhiyamaan college of engineering, assistant professor, hosur, India2. Adhiyamaan college of engineering, hosur, India. Experimental Study on Flexural Behavior of Bendable Concrete.

5. K.Selvakumar1, R.Kishore kumar2, A.Deivasigamani3, Ms.S.Amutha4 Student, Civil, Sri Muthukumaran Institute of technology, Chennai, India1 Student, Civil, Sri Muthukumaran Institute of technology, Chennai, India. 2 Student, Civil, Sri Muthukumaran Institute of technology, Chennai, India. 3 Assistant Professor, Civil, Sri Muthukumaran Institute of technology, Chennai, India4. Experimental study on bendable concrete.

6. Dr. A. W. Dhawale1, Mrs. V. P. Joshi21 Associate Professor \& PG Coordinator, Imperial College of Engineering \& Research Wagholi, Pune.2Assistant Professor Paravatibai Genba Moze College of Engineering,, Pune. Engineered Cementitious Composites for Structural Applications. 